\title{
Extracting Winter Wheat Planting Area Based on Cropping System with Remote Sensing*
}

\author{
Xueyan Sui ${ }^{1}$, Xiaodong Zhang ${ }^{1}$, Shaokun $\mathrm{Li}^{2,3,{ }^{* *}}$, Zhenlin Zhu ${ }^{1}$, Bo Ming ${ }^{2}$, \\ and Xiaoqing Sun ${ }^{1}$
}

${ }^{1}$ Institute of Agriculture Sustainable Development/Shandong Academy of Agriculture Sciences, Jinan 250100, China

Tel.: 0531-83179362

yeyatousxy@163.com

${ }^{2}$ Institute of Crop Sciences, Chinese Academy of Agriculture Sciences/ Key Laboratory of Crop Physiology and Production Ministry of Agriculture, China, Beijing 100081, China

Tel.: 010-82108891

Lishk@mail.caas.net.cn

${ }^{3}$ Key Laboratory of Oasis Ecology Agriculture of Xinjiang Construction Crops/ The Center of Crop High-yield Research, Shihezi 832003, China

\begin{abstract}
Winter wheat is one kind of important crop in China. It's planting area is one key element to explain yield change. To obtain winter wheat planting area as soon as possible can provide scientific reference for our country's making related policy. Basing on the cropping system in Shandong province, winter wheat is divided into two kinds "winter wheat sowed by machine-maize" and "people broadcast winter wheat-rice". Using MODIS data, NDVI characters of winter wheat, garlic, greenhouse vegetable, from sowing till overwintering stage were analyzed. Together with NDVI characters of former stubble crops in middle September, extracting requirements were set up for winter wheat planting area which was sowed by machine this year. In view of the spectrum similarity between rice wheat and greenhouse vegetable from sowing stage till overwintering stage, rice wheat planting area of former year was extracted relying on the character of biomass rapid growth at jointing stage. Because of the "people broadcast winter wheat-rice" cropping system is very fixed in Shandong province, then the rice wheat planting area of former year can take the place of the rice wheat planting area this year. Two kinds of winter wheat area were merged, and tested by 284 groups of located spots data, the accuracy reached $94.01 \%$. The result showed that it is feasible to extract winter wheat area before overwintering stage, and the time is 4 months earlier than using jointing stage NDVI.
\end{abstract}

Keywords: Shandong province, winter wheat, rice wheat, area, remote sensing.

\footnotetext{
* Fund projects: National Science \& Technology Pillar Program (2007BAH12B02); Shandong Academy of Agricultural Sciences innovation program (2007YCX026); Shandong Province Science \& Technology development projects (2009GG10009007).

* Corresponding author.
} 


\section{Introduction}

Shandong Province located in the Huang-Huai Plain is the major winter wheat producing area in China. It is important to grasp winter wheat area timely and accurately for the country's food security. In the past, winter wheat area mainly relied on primary agricultural production sectors' artificial survey and then statistics level by level. Limited resources and subjectivity led to poor data, which brought some impact to government's decision on agriculture production. With the development of science and technology, In 1980s, remote sensing had become one tool of agriculture resource investigating and crop growth monitoring with characters of obtaining data objectively, accurately and timely [1].The key to extract winter wheat area is the data resource and the choice of phase. In 1990s, using NOAA satellite data, Maoxin Wang set up regression equation of winter wheat area and the pixel number whose NDVI (Normal Differential Vegetation Index) difference between November and October was greater than zero [2]. A large population but less land area, complex cropping system and NOAA satellite data's lower spatial resolution resulted that the extracting accuracy of winter wheat was not high. In the 21 st century, with the food strategy advancement, some regions extracted winter wheat area with TM and spot data [3, 4] which holds higher spatial resolution than NOAA data. Extracting methods included visual interpretation [5], supervised classification [6], unsupervised classification [7, 8] and pure pixel identification based on spectral library [9]. Although resolution being enhanced and data processing technology being improved have made the accuracy reach over $90 \%$, While TM data has lower time resolution and easily influenced by weather, what's more the cost is high, then TM data can only be used to invest winter wheat areas of small regions but not large areas.

Compared with NOAA data and TM data, MODIS data has higher time and middle spatial resolution. The data sharing service has made MODIS data be used to remote sensing monitoring winter wheat more and more [10-13]. Yigang Jing set models and extracted winter wheat area with accuracy of over $91 \%$ using the NDVI changes of March, May and June [14]. Jinqiu Zou extracted area using the EVI (Enhanced Vegetation Index) difference between May and October, and the error rate was $-0.04 \%$ [15]. Wenpeng Lin used NIR, RED, BLUE and ESWIR 4 bands MODIS data of October and December to class 6 kinds of surface features with the method of fuzzy ARTMAP, and the accuracy reached $80.3 \%$ [16]. The main method of comparing spectral changes in the key growth periods after sowing for extracting winter wheat area was used frequently using MODIS data [17]. Over time, the amount of information increased, and the accuracy enhanced [18-20]. The paper studied one method with high accuracy to extract winter wheat area at early periods, combining with the former stubble crops based on cropping system in Shandong province.

\section{Data Acquisition}

Winter wheat is sowed in middle to late October in Shandong province, and tillers in early to middle December. In middle to late October, most vegetables in greenhouse are transplanted, and grow fast after rejuvenation in December, and the change of NDVI is similar with that of winter wheat, which influences the extracting accuracy of winter 
wheat area [16]. Shandong province is also the major producing area of garlic. It is sowed in late September to early October, the growing condition is very similar to winter wheat in winter, and thus it is another important obstacle.

In order to exclude the interferences of greenhouse and garlic, discussion group located 284 spots of six kinds of surface features which included winter wheat, greenhouse vegetable, garlic, village, uncovered cotton filed, tree, in Shandong province, in late October, 2008. Downloaded MOD09Q1 data of the 284 spots of middle January, middle April, middle September, middle October and middle December, form MODIS data sharing platform-ftp://e4ft101u.ecs.nasa.gov/.

\section{Data Analysis}

\subsection{This Part Analyzed Surface Features' NDVI Sequence, and Set Up Identification Conditions to Extract Winter Wheat Area Preliminarily}

We calculated the located spots' NDVI and the average of middle September, middle October and middle December for six kinds of surface factures separately, and then drew line chart (fig. 1). The NDVI of cotton filed dropped as the season went on, and it was similar to village and tree. Among the three periods, the NDVI in September was the highest for winter wheat, greenhouse vegetable and garlic, at that time, winter wheat filed and garlic filed are all planted maize, and greenhouse is still planted vegetable. The gain period of garlic is in late May, which is earlier than winter wheat. After garlic the filed is planted with early mature maize, and the maize is gained in middle to late September. While winter wheat is gained in middle June, then the filed is planted with maize. Winter wheat field's maize is at filling period, so the NDVI average 0.71 in middle September is higher than that of garlic filed. Till middle October, maize is gained, and winter wheat is sowed. Garlic is sowed in late September to early October, and the time of emergence is earlier than winter wheat. Greenhouse

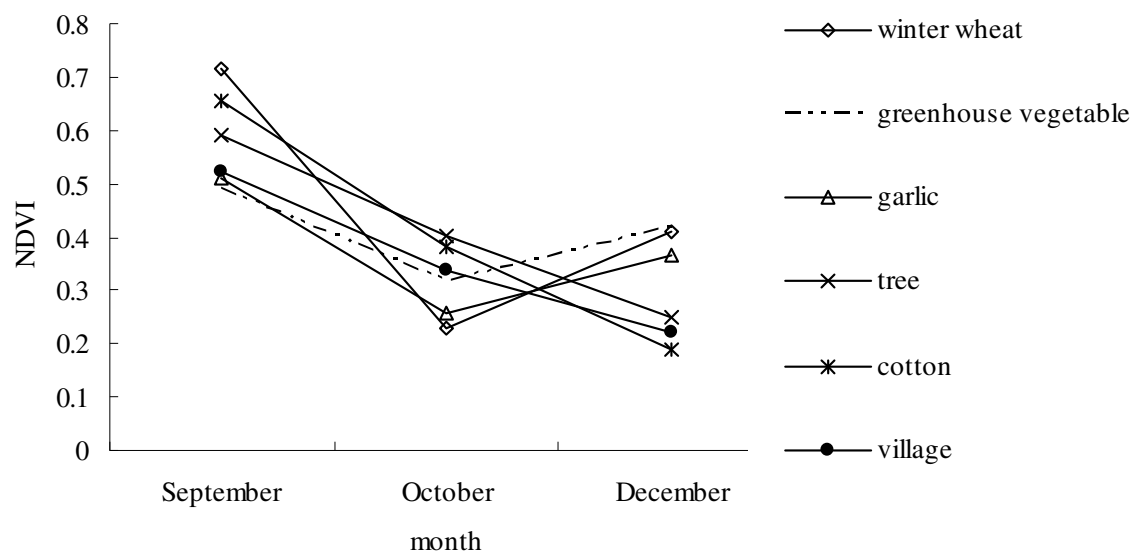

Fig. 1. NDVI line chart of 6 kinds of surface features in the three periods 
vegetable is transplanted, and grows faster than winter wheat and garlic with good conditions. Thus greenhouse vegetable's NDVI is higher than garlic field's, and garlic field's NDVI is higher than winter wheat field's. In middle December, winter wheat steps into tillering stage, and reaches growing peak before winter. Garlic's biomass and greenhouse vegetable's biomass all continues to increase. So in middle December, the three kinds surface features' NDVI are all higher than that in middle October, but lower than in middle September. According to the analysis above all, preliminary identification conditions were set up to extract winter wheat area: NDVI middle September $>$ NDVI middle December $>$ NDVI middle October, and NDVI middle September $>0.5$ 。

\subsection{Test on Identification Result}

Used the identification conditions to extract winter wheat area, and tested the result with 284 groups of located spots' data (table 1).

Table 1. The test results checklist

\begin{tabular}{ccccc}
\hline Surface features & $\begin{array}{c}\text { The number of } \\
\text { spots to be tested }\end{array}$ & $\begin{array}{c}\text { The number of spots } \\
\text { tested to be Winter Wheat }\end{array}$ & $\begin{array}{c}\text { The number of spots } \\
\text { tested to be others }\end{array}$ & Wrong test reasons \\
\hline $\begin{array}{c}\text { winter wheat } \\
\text { cotton }\end{array}$ & 161 & 138 & 23 & $\begin{array}{c}\text { mixed pixels } \\
16 \text { rice wheat }\end{array}$ \\
$\begin{array}{c}\text { greenhouse } \\
\text { vegetable }\end{array}$ & 31 & 0 & 24 & mixed pixels \\
$\begin{array}{c}\text { garlic } \\
\text { tree }\end{array}$ & 11 & 3 & 8 & mixed pixels \\
village & 26 & 3 & 25 & $\begin{array}{c}\text { mixed pixel } \\
\text { mixed pixels }\end{array}$ \\
\hline
\end{tabular}

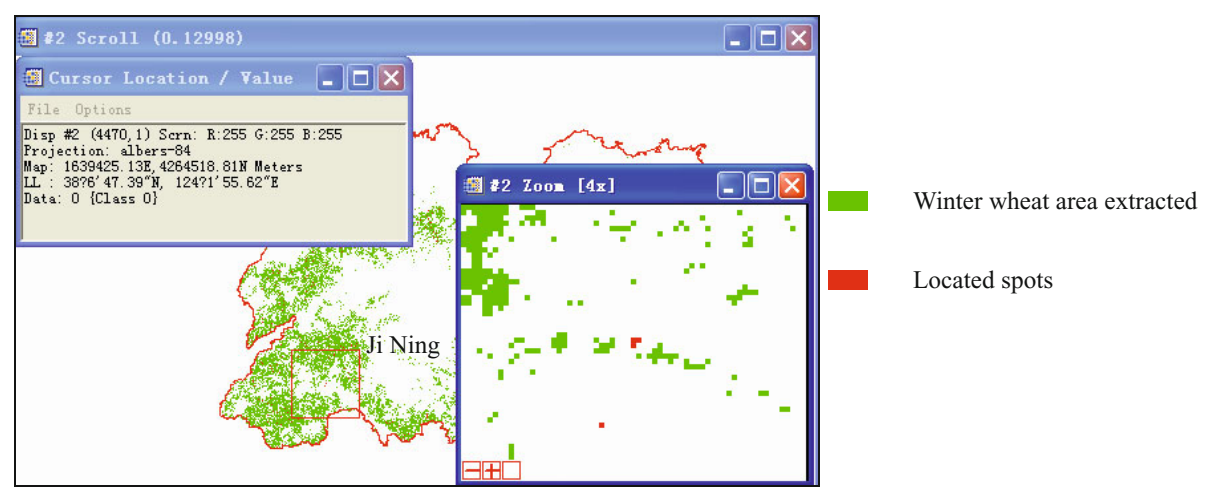

Fig. 2. Spots of rice wheat tested to be others 


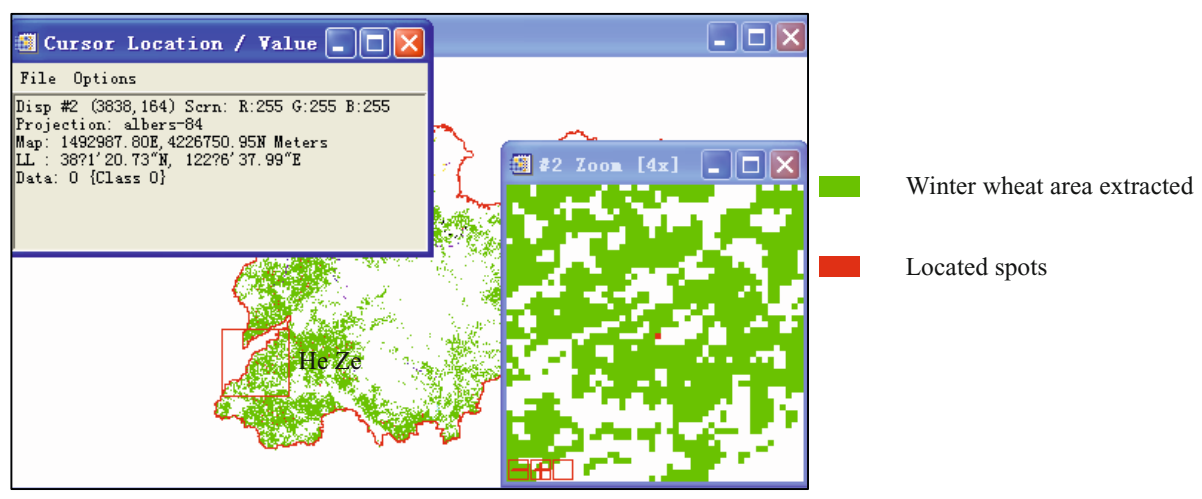

Fig. 3. Mixed pixel of winter wheat tested to be others

The result was listed in table 1. Among 284 located spots, 23 winter wheat spots were identified to be other surface features. 10 other surface features spots were identified to be winter wheat, which included 3 greenhouse vegetable spots, 3 garlic spots, 1 tree spot and 3 village spots. Imported the 284 groups of located spots into ENVI, and inspected one by one, then discovered that the wrong identifications can be divided into two kinds of situations: one was located spots were mixed pixels of winter wheat with greenhouse vegetable, garlic, tree or village (fig. 2); the other was rice wheat spots were identified to be other surface features (fig. 3). A large population but less land area and complex cropping system in Shandong province make the phenomenon of mixed pixels inevitable. Rice wheat was not identified, showed the identification conditions didn't contain rice wheat information. Only extracted "winter wheat sowed by machine-maize" area, so the main task remained was to extract "people broadcast winter wheat-rice" area.

\subsection{The Extraction of Rice Wheat Area}

Calculated 16 rice wheat spots' average NDVI of the 3 periods, compared with common winter wheat. As fig.4, fig5 showed, in September, rice is growing in rice wheat field, and maize is growing in winter wheat field, and the NDVI of rice is lower than that of maize. In middle October rice is gained, and rice wheat is at trefoil stage which was broadcasted not long ago, whose NDVI is higher than normal wheat. What's more rice wheat field has adequate water supply, so rice wheat growing condition is better than normal winter wheat till middle December. During the analyzing progress, narrowing NDVI threshold of the 3 periods was tried to extract rice wheat area, but failed for the NDVI similarity between rice wheat and greenhouse vegetable.

Winter wheat goes into overwintering stage In January, and jointing stage in April, growing condition is influenced by air temperature; rice wheat and normal winter wheat are similar to each other. So it is possible to extract all winter wheat area depending on NDVI fast increasing over the period from middle January to middle April, that is to say, from overwintering stage to jointing stag. This method is popular now. 


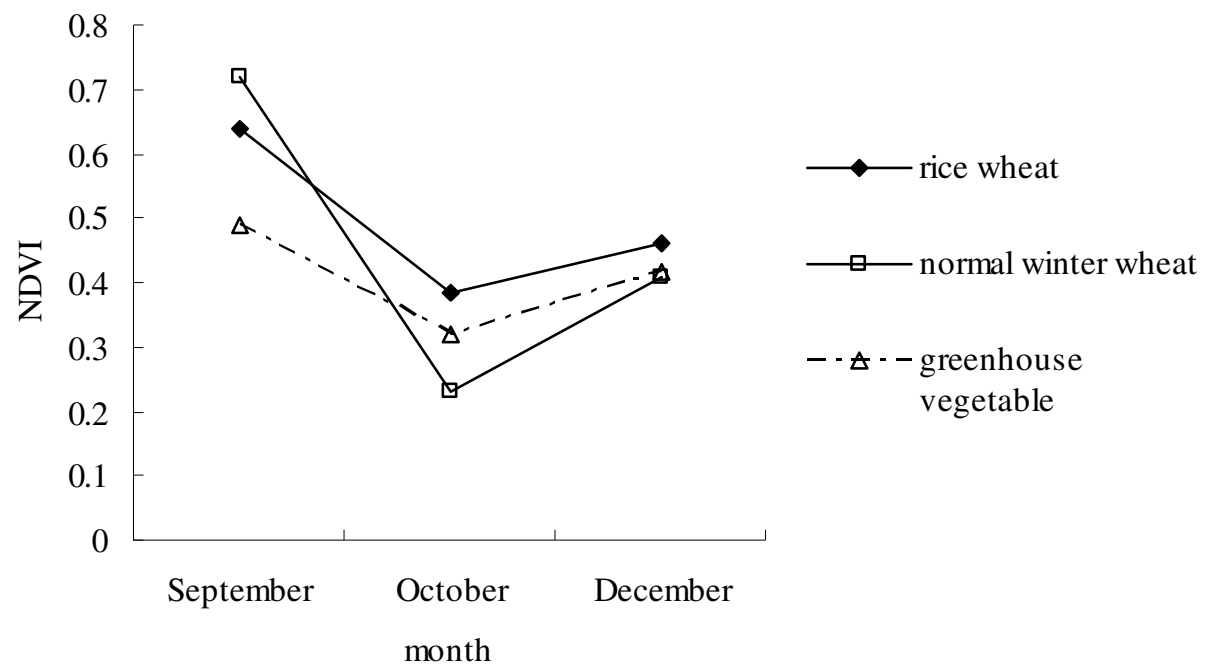

Fig. 4. NDVI line chart of rice wheat, normal winter wheat, greenhouse vegetable in the three periods
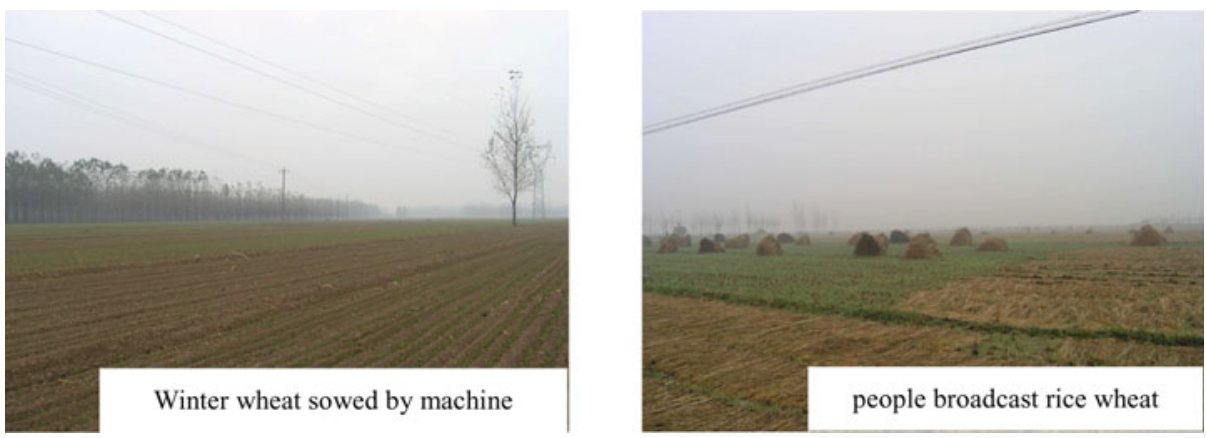

Fig. 5. Winter wheat sowed by machine and people broadcast winter rice wheat in middle to late October

Affected by geographical environment and climate, "people broadcast winter wheat-rice" is one common cropping system in Yellow River Basin and the Southern Four Lakes rim, so the rice wheat field is relatively fixed. According to Statistical Yearbook, vector graph of rice planting region was set up in Shandong province with the help of ARCVIEW. The normal winter wheat area which has been extracted with data of middle September, middle October, middle December was named S1. The rice wheat area extracting conditions were set up, (NDVI middle April - NDVI middle January) $>0.19$, NDVI middle January $>0.3$, and NDVI middle September $>0.5$, using the data of 2008. In ENVI, S1 was masked, and among rice wheat field vector region, rice wheat area was extracted of 2007-2008, which were named S2 (fig. 6). The 16 rice wheat located spots were all extracted successfully. 


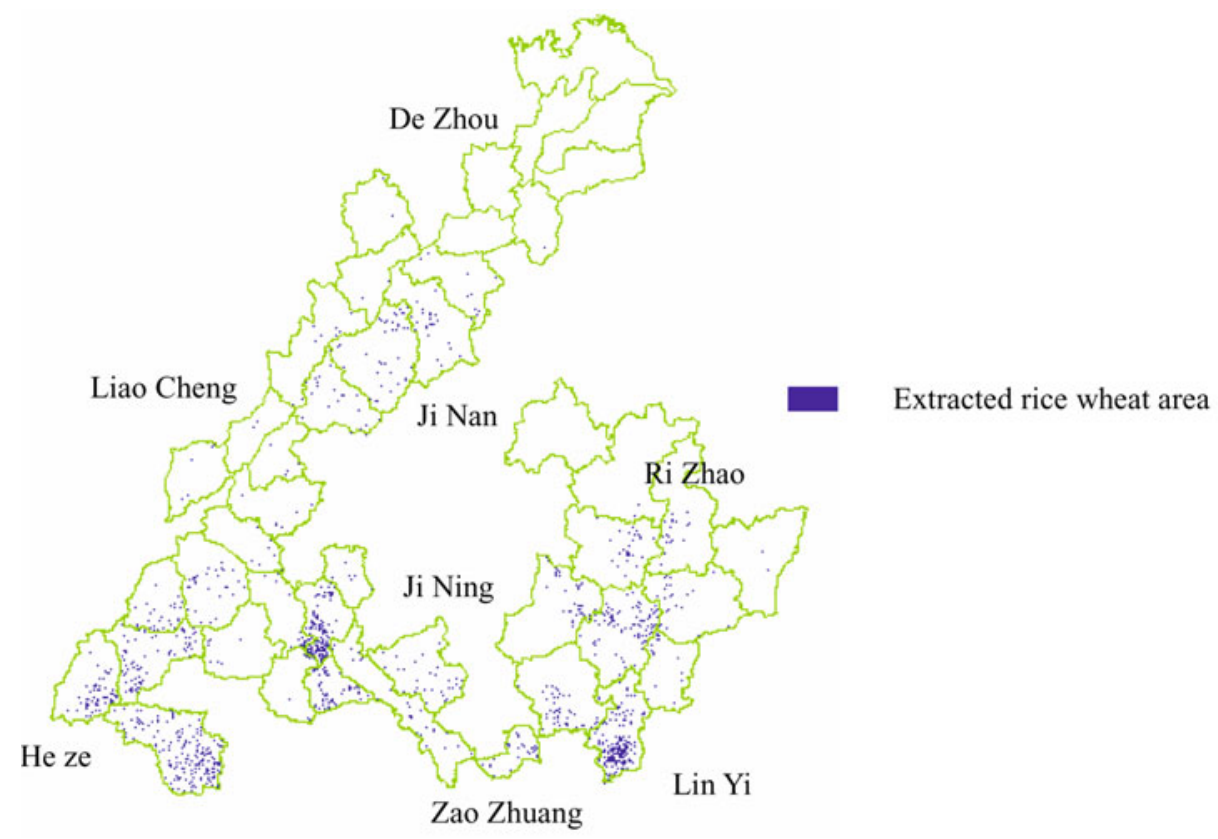

Fig. 6. The extracted area of rice wheat of 2007-2008

\subsection{The Extraction of all Winter Wheat}

The two parts S1 and S2 of winter wheat were merged, which contained the normal winter wheat area extracted with the data of September, October, and December, 2008,

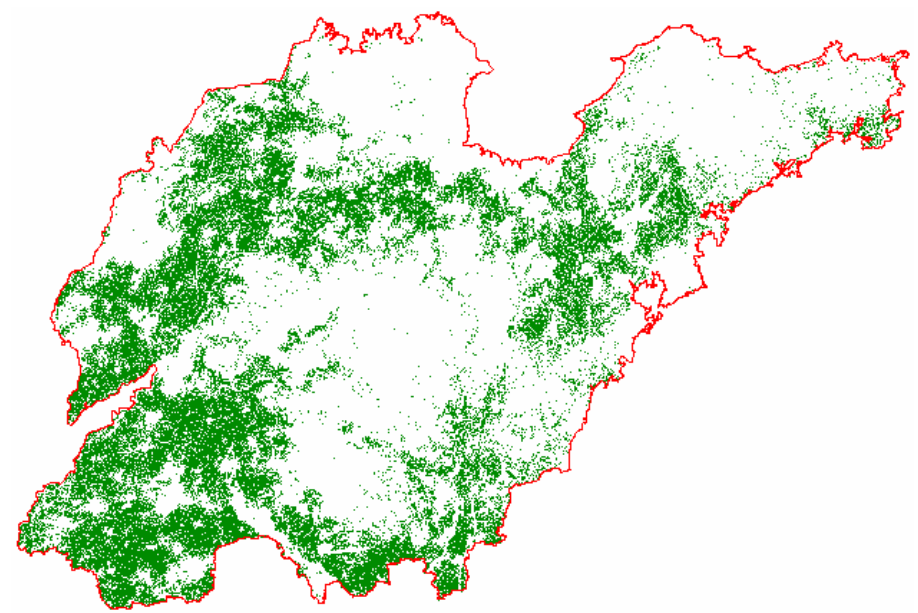

Fig. 7. The extracted area of winter wheat of Shandong province of 2008-2009 
and the rice wheat area extracted with the data of January, April, and September, 2008. The total winter wheat area of 2008-2009 was $4480666.67 \mathrm{hm} 2$, tested by the located spots' data the accuracy was $94.01 \%$ (fig. 7).

\section{Result and Discussion}

Winter wheat in Shandong province can be divided into two kinds from a cropping system point of view, "mechanical sowing winter wheat-maize" and "people broadcast winter wheat-rice". The paper studied NDVI characters of winter wheat, garlic and greenhouse vegetable from seeding time October to overwintering stage December. The study showed that 3 kinds of surface features' NDVI changing tendencies are similar to each other, and it is difficult to extract winter wheat area. Together with the difference of the previous crop's NDVI, the normal winter wheat of "mechanical sowing winter wheat-maize" was extracted. But the rice wheat NDVI of "people broadcast winter wheat-rice" is similar to greenhouse vegetable NDVI, so it is impossible to extract rice wheat area just depending on the change of NDVI. Based on the special growing environment of rice wheat, rice plant region vector in Shandong province was set up. Among this region, rice wheat area of the previous year was extracted using the fast NDVI increase at jointing stage than overwintering stage. The two parts winter wheat area were added up, and got the total area in late December.

This study used middle spatial resolution and high time resolution MODIS data to settle the interference of garlic and greenhouse vegetable to winter wheat area extracting in Shandong province. The extracting time was 4 months in advance than using jointing stage NDVI character[21,22], and the accuracy reached $94.01 \%$, so the method can meet the demand of large area.

Natural environment decides cropping system, while the improvement of agricultural production technology, and many other economical factors' all influence the reform of cropping system. So using the previous year rice wheat area to take the place of the current year will affect the accuracy of total winter wheat area. In future research, rice field's spectrum should be studied, and assisted with NDVI change character of rice wheat from seeding to overwintering stage to extract rice wheat area, in order to enhance the total winter wheat area extraction accuracy.

\section{References}

1. Mei, A., Peng, W., Qin, Q., et al.: Introduction to Remote Sensing. Higher Education Press, Beijing (2001)

2. Wang, M., Pei, Z., Wu, Q., et al.: Winter wheat sown area estimation using NOAA AVHRR data. Transactions of the CSAE 14, 84-88 (1998)

3. Murakami, T., Ogawa, S., Ishitsuka, M., et al.: Crop discrim-ination with multitemporal SPOT/HRV data in the Saga Plains, Japan. Int J. Remote Sens. 22, 1335-1348 (2001)

4. Qi, L., Liu, L., Zhao, C., et al.: Selection of optimum periods for extracting winter wheat based on multi-temporal remote sensing images. Remote Sensing Technology and Application 23, 154-160 (2008) 
5. Gu, X., Pan, Y., Zhu, X., et al.: Consistency study between MODIS and TM on winter wheat plant area monitoring — a Case in small area. Journal of Remote Sensing 11, 350-357 (2007)

6. Feng, M., Yang, W., Zhang, D., et al.: Monitoring planting area and growth situation of irrigation-land and dry-land winter wheat based on TM and MODIS data. Transactions of the Chinese Society of Agricultural Engineering 25, 103-109 (2009)

7. Huang, X., He, W., Zhang, Y., et al.: Monitoring on wheat area using TM in some areas of Jiangsu province. Jiangsu Agricultural Sciences, 85-87 (2003)

8. Li, W., Li, H., Wang, J., et al.: A study on classification and monitoring of winter wheat growth status by Landsat/TM image. Journal of Triticeae Crops 30, 92-95 (2010)

9. Chen, S.: Remote sensing method of pure crop pixel identification and planting area estimation based on spectral library. Chinese Academy of Science, Beijing (2005)

10. Yang, X., Zhang, X., Jiang, D.: Extraction of multi-crop planting areas from MODIS data. Resources Science 26, 17-22 (2004)

11. Wu, Y., Wang, Y., Zhang, J., et al.: Linear mixture modeling applied to remote sensing monitoring of winter wheat areas. Transactions of the Chinese Society of Agricultural Engineering 24, 136-140 (2009)

12. Yan, F., Wang, Y., Wu, J., et al.: Extracting winter wheat area using temporal sequence of Ts-EVI. Transactions of the CSAE 25, 135-140 (2009)

13. Qiao, H., Zhang, H., Cheng, D.: Application of EOS/MODIS-NDVI at different time sequences on monitoring winter wheat acreage in Henan Province. Journal of Anhui Agricultural Sciences 36, 11940-11941 (2008)

14. Jing, Y.: Study on extracting winter wheat area using EOS/MODIS data. Shanxi Journal of Agricultural Sciences (2), 95-98 (2008)

15. Zou, J., Chen, Y., Uchida, S., et al.: Method for extracting winter wheat area using Terra/MODIS data and its accuracy analysis. Transactions of the Chinese Society of Agricultural Engineering 23(11), 195-200 (2007)

16. Lin, W.: Study on crop information extraction based on MODIS spectral analysis. Chinese Academy of Science, Beijing (2006)

17. Zhang, M., Zhou, Q., Chen, Z., et al.: Crop acreage change detection based on phenology model. Transactions of the CSAE 22, 139-144 (2006)

18. Wang, Y., Shen, R., Tian, G.: Study on Extracting Winter Wheat Planting Area Based on MODIS Data by Spectral Mutation. Nei Menggu Weather, 18-21 (2009)

19. Wang, Y., Shen, R.: Study on the Planting Area Extraction of Winter Wheat Based on MODIS Data. Journal of Anhui Agricultural Sciences 37, 16694-16696 (2009)

20. Xu, W., Zhang, G., Fan, J., et al.: Remote sensing monitoring of winter wheat areas using MODIS data. Transactions of the CSAE 23, 144-148, 196 (2007)

21. Qin, Y., Zhao, G., Jiang, S., et al.: Winter wheat yield estimation based on high and moderate resolution remote sensing data at county level. Transactions of the CSAE 25 , 118-123 (2009)

22. Chen, J., Liu, H., Huang, Y., et al.: Analysis on the Multi-temporal Features of MODIS/NDVI in the Growing Period of Winter Wheat and Its Application in Ground-object Identification. Journal of Anhui Agricultural Sciences 38, 3641-3643, 3667 (2010) 